\title{
Refractory errors in medical students in a teaching hospital in rural Telangana
}

\author{
N. Karthika ${ }^{1}$, Kumari R. ${ }^{2}$, Kumar A. ${ }^{3}$ \\ ${ }^{1}$ Dr. N. Karthika, Associate Professor, ${ }^{2}$ Dr. Rathna Kumari, Senior Resident, ${ }^{3}$ Dr. Ashok Kumar, Professor \& Head; all \\ authors are affiliated with Department of Ophthalmology, MediCiti Institute of Medical Sciences, Medchal, Mandal, \\ Ghanpur, Telangana- 501401, India.
}

Corresponding Author: Dr. N. Karthika, Associate Professor, Department of Ophthalmology, MediCiti Institute of Medical Sciences, Medchal, Mandal, Ghanpur, Telangana- 501401, India. E-mail: resdoc555@gmail.com

\begin{abstract}
Introduction: Refractive errors are attributing to major public health problem. The increasing prevalence rates of myopia have reached to epidemic proportions in many Asian countries. This study was done to determine the prevalence rates of refractive errors in medical students. Methods: About 350 medical students (aged 19-23 years) of MediCiti Institute of Medical Sciences were examined. Refractive error measurements were determined using an autorefractor. Demographical data was obtained by questionnaires filled in by the students. Results: A total of 176 students (40\%) of 350 students had refractive errors. A female pre-ponderance was observed. 104 females (59\%) and 72 (41\%) males. Myopia was seen in $70.45 \%$, Hyperopia was present in $6.8 \%$ of the participants and the astigmatism prevalence rate was $38 \%$. Conclusion: Myopia was the predominant refractive error among the medical students. Hence, timely intervention is the hour of the need as correction of refractive error will increase the productivity thus benefiting the society and the country.
\end{abstract}

Key words: Astigmatism, Myopia, Prevalence rates, Hypermetropia, Medical students

\section{Introduction}

Refractive error (RE) is defined as a condition in which the non-accommodating eye's optical system is unable to focus parallel rays of light on the retina. Among all the human senses, the sense of sight is used themost, and is affected the most. Consequently, refractive errors are attributing to major problem in the community. The usage of spectacles was a province of adults over 40 years age till half century earlier. In the recent times, we find more children and adolescents wearing spectacles. Refractive errors are one of the commonest reason for patients to visit an ophthalmologist. It is the second most common cause of blindness in developing countries such as India [1].

A total of 153 million with a prevalence of $2.67 \%$ have uncorrected Refractive errors, world-wide, while in India a totalof 39.31 million with prevalence of $4.07 \%$, have uncorrected refractive errors [1]. Uncorrected refractive errors will have a significant impact on learning, can cause academic failure which in the long

Manuscript received: $15^{\text {th }}$ July 2018

Reviewed: $28^{\text {th }}$ August 2018

Author Corrected: $4^{\text {th }}$ September 2018

Accepted for Publication: $8^{\text {th }}$ September 2018 run leads to economic burden on family and in turn to the society. The most common type of refractive error is myopia while presbyopia is considered as a natural process of ageing. The prevalence rateof myopia in Asian countries have reached epidemic proportions [2].

The prevalence rates of Refractive errors were high among the highly educated persons [3]. Mean while, myopes have been reported to achieve higher intelligence test scores and higher educational levels than non- myopes [4]. Medical students spend lot of time on reading and close-up work. They are a select population with a high level ofeducation as well as above average intelligence. The curriculum of medical students includes intensive study regimen that spans many years, hence, medical students are at high risk for developing myopia[5]. Adult onset myopia isalso thought to be a common occurrence in medical students $[6,7]$.

Uncorrected refractive error stands next to cataract in causing global visual impairment. It has a significant impact on learning and academic success [8]. High 
prevalence rate of refractive errors was seen among medical students. Most of the studies on refractive errors have primarily focused on school going childrenin different parts of India. Very little is known about the prevalence of refractive errors in medical students. In this study we have included under graduate medical students of MIMS. As the refractive errors are frequently more prevalent among students pursuing higher education, It is believed that the information obtained from this study will help in making future planning and rendering better eye care services.

\section{Materials \& Methods}

A prospective study was conducted in the department of Ophthalmology, MediCiti Institute of Medical Sciences, Medchal, over a period of one year from January 2017 to December 2017. Medical students were randomly selected for this study. A totalof 350 students were included in this study. Institutional ethical committee approved the study. Aninformed consent was obtained from the subjects. All students under went a complete ophthalmic examination, including detailed history of ophthalmic and systemic problems.

Students were examined by assessing the visual acuity from a standard Snellen's chart for far vision and Jaeger's chart for near vision. The test of possible defect of color vision was conducted with the help of Ishihara pseudo isochromatic color plates. All students were assessed for refractive errors using auto-refractometer.

The refractive errors: myopia, hyperopia and astigmatism were categorized in the following way Category: 1 - from 0.25 to $0.99 \mathrm{D}$, category: $2 ; 1.0$ to 2.99D, category: $3 ; 3.00$ to $5.99 \mathrm{D}$ and category: $4 ; 6 \mathrm{D}$ or greater. Those having a visual acuity less than $6 / 6$ in one or both eyes were tested for the presence of a refractive error by Pinhole testing [indicating refractive error. Prevalence of refractive errors was calculated as a ratio of subjects detected to have refractive errors, per hundred medical students.
Inclusion criteria- MBBS First to third year in the age group of 18 -23years and of both sexes were included.

\section{Exclusion criteria}

- diabetes mellitus

- any eye abnormality,

- present or past history of any eye diseases,

- genetic diseases

- history of trauma to eye ,

- history of retinopathy,

- prematurity,

- connective tissue diseases associated with refractive errors

Procedure- The visual acuity was tested at 6 meters and if uncorrected vision was less than 6/9 in either eye, the child was declared to have defective vision. All students with defective vision were examined by the refractions. Vision was repeated with pin hole and appropriate spectacle correction was given. Children already wearing spectacles were also examined and any change in refractive error was noted. Myopia was considered when the measured refraction was more than or equal to -0.5 diopters spherical equivalent in one or both eyes. Hypermetropia was considered when the measured objective refraction was greater than or equal to +1.00 diopters spherical equivalent in one or both eyes. Astigmatism was considered to be visually significant if $\geq 1.00$ D. The visual acuity, types of refractive error and spectacle correction were noted down

Statistical Analysis- Significance was assigned at $P<$ 0.05 level for all parameters. Categorical variables were compared with the $\chi^{2}$ test or the Fisher exact test. The $t$ test was used for continuous variables. The Pearson coefficient of correlation was used to compare subjective and objective refraction and right and left eye refraction. Multivariate analyses were performed with logistic regression.

\section{Results}

A total of 350 students were examined. A female preponderance was observed in this study with 104 (59\%) females and $72(41 \%)$ were males. The age of ametropic students ranged from 19-24 years. About 176 students had refractive errors (40\%), of these, 124 had myopia (70.45\%), 67 had astigmatism (28\%) and 12 had hypermetropia (6.8\%)(table1)

Table-1: frequency of refractive error.

\begin{tabular}{|c|c|c|}
\hline Refractive error & Number & Percentage \\
\hline Myopia & 124 & 70.45 \\
\hline Astigmatism & 67 & 28 \\
\hline Hypermetropia & 12 & 6.8 \\
\hline
\end{tabular}


Table 2: Information regarding medical students.

\begin{tabular}{|c|c|c|c|}
\hline Batch & Myopia & Astigmatism & Hypermetropia \\
\hline $\begin{array}{c}1 \text { stbatch } \\
(\mathrm{n}=100)\end{array}$ & 36 & 22 & 3 \\
\hline $\begin{array}{c}2 \mathrm{nd} \text { batch } \\
(\mathrm{n}=100)\end{array}$ & 36 & 19 & 7 \\
\hline $\begin{array}{c}3 \mathrm{rd} \text { batch } \\
(\mathrm{n}=150)\end{array}$ & 52 & 26 & \\
\hline
\end{tabular}

Positive family history was seen in $30 \%$ students with refractive errors. Among those with refractive errors, only $50 \%$ had regular annual ophthalmic checkups. Others went for a review only when they were symptomatic (headache, defective vision). Only 32\% got their fundus checked with indirect ophthalmoscopy (to rule out presence of any degenerative changes). About $35 \%$ had a habit of reading in moving vehicles.

\section{Discussion}

The long and intensive study regimen of medical school involves extensive near work such as reading and writing. It has been suggested that the amount of near work could cause myopia as well as its progression in adulthood [5,9]. It is possible that medical school may be a surrogate factor for intensive near work activity. It has been suggested that the amount of near work could cause myopia as well as its progression in adult hood [10-12]. It has been hypothesized that an underlying genetic predisposition may alter eye growth [13,14]. However, it is now generally agreed that both heredity and the environment have important roles to play. It is possible that differences in myopia prevalence rates in medical students across different countries may be attributable to ethnic variations and different genetic predispositions. Medical students are a select population with a high level of education as wellas above average intelligence. This might explain the high prevalence rates of myopia among medical students. [11]

Table-2: Prevalence of myopia in medical students: comparison with global data [2,6-7, 15-18].

\begin{tabular}{|c|c|c|}
\hline Country & Author & Prevalence\% \\
\hline Taiwan & Lin LL, et al & 93 \\
\hline Singapore & Woo WW, et al & 71 \\
\hline China & Wu Y, et al & 70.7 \\
\hline India & Jyothirmai et al & 58 \\
\hline Pakistan & Chuaday R, et al & 58 \\
\hline Norway & Midelfart A, et al & 50 \\
\hline Denmark & Fledelius HCet al & 32 \\
\hline Poland & Mozolewska- Piotrowska K, et al & 33 \\
\hline Turkey & Onal S et al & 35 \\
\hline Present study & Karthika et al & 33 \\
\hline
\end{tabular}

The higher rate of refractive errors in medical students was probably due to high-level of educational achievement, above average intelligence, long and exhaustive study schedule, and prolonged near-work. With their rigorous study schedule that spans on the average 5 to6 years, they have been reported to be at high risk for myopia [2,21,22].

The precise pathogenic mechanisms of the myopisation of ocular refractive machinery by near-work are yet to be fully established. According to recent theory blurred retinal image that occurs during prolonged near work leads to myopia. This blurring of retinal images stimulates biochemical and structural changes in the sclera and choroid that lead to axial elongation. [22] 
These differences found globally maybe attributed to various ethnicities, environmental factors. This study and other various studies observed that myopia is more prevalent among more intelligent population. The present study and many previous studies supported the observations that - Myopia is multifactorial with genetic and environmental factors and interaction between them, as well as - parental history of myopia is an important risk factor for its development which was reported in various studies [15-18]. The present study has also observed a marginal increase in the amount ofnear work done by those with refractive errors which was in correlation with the findings observed by Woo etal [2].

\section{Conclusion}

Myopia was the predominant refractive error among the medical students. Hence, timely intervention is the hour of the need as correction of refractive error will increase the productivity, thusbenefiting the society andthe country.

\section{Funding: Nil, Conflict of interest: Nil \\ Permission from IRB: Yes}

\section{References}

1. Resnikoff S, Pascolini D, Mariotti SP, Pokharel GP. Global Magnitude of Visual Impairment Caused by Uncorrected Refractive Errors in 2004. Bulletin of the World Health Organization; 2004. p. 2. Available from: http: // www. who.int/ bulletin/volumes/ 86/1/07041210/en

2. Woo WW, Lim KA, Yang H, et al. Refractive errors in medical students in Singapore. Singapore Med J. 2004 Oct;45(10):470-4.

3. Saw SM, Katz J, Schein OD, et al. Epidemiology of myopia. Epidemiol Rev. 1996; 18 (2) : 175 87.

4. Teasdale TW, Fuchs J, Goldschmidt E. Degree of myopia in relation to intelligence and educational level. Lancet. 1988 Dec 10;2(8624):1351-4.

5. Shulkin DJ, Bari MM. Deteriorating vision: an occupational risk for the medical student. Arch Ophthalmol. 1986 Sep;104(9):1274.

6. Fledelius HC. Myopia profile in Copenhagen medical students 1996-98. Refractive stability over a century is suggested. Acta Ophthalmol Scand. 2000 Oct; 78 (5): 501-5.

7. Midelfart A, Aamo B, Sjøhaug KA, Dysthe BE. Myopia among medical students in Norway. Acta Ophthalmol (Copenh). 1992 Jun;70(3):317-22.

8. Megbelayin EO. Barriers to uptake of prescribed refractive spectacles amongst Nigerian students. Int. Res.J. Basi Clin. Stud. 2013;1(5):71-77.
9. Chow YC, Dhillon B, Chew PT, Chew SJ. Refractive errors in Singapore medical students. Singapore Med J. 1990 Oct;31(5):472-3.

10. Saw SM, Nieto FJ, Katz J, Chew SJ. Estimating the magnitude of close-up work in school-age children: a comparison of questionnaire and dairy instruments. Ophthalmic Epidemiol 1999; 6:291-301. Singapore Med J 2004 Vol 45(10) : 474

11. Kinge B, Midelfart A, Jacobsen G, Rystad J. The influence of near-workon development of myopia among university students. A three-year longitudinal study among engineering students in Norway. Acta Ophthalmol Sc and 2000; 78:26-9.

12. Saw SM, Wu HM, Seet B, et al. Academic achievement, close up work parameters, and myopia in Singapore military conscripts. Br J Ophthalmol. 2001 Jul; 85 (7):855-60.

13. Yap M, Wu M, Liu ZM, et al. Role of heredity in the genesis of myopia. Ophthalmic Physiol Opt. 1993 Jul;13(3):316-9.

14. Chew SJ, Ritch R. Parental history and myopia taking the long view. JAMA 1994; 272:1255-1256

15. Chaudhry R, Ali H, Sheikh NH. Frequency and underlying factors of myopia among medical students. Biomedica2011;27:154-60.

16. T. Jyothirmai, V. Meenakshi, S.V Padmavathi. A Study on Refractive Errors Among Medical Students Attending Ophthalmology Department. IOSR-JDMS 2017; 16(10): 57-61

17. Onal S, Toker E, Akingol Z, et al. Refractive errors of medical students in Turkey: one year follow-up of refraction and biometry. Optom Vis Sci. 2007 Mar;84 (3): $175-80$.

18. Lin LL, Shih YF, Lee YC, et al. Changes in ocular refraction and its components among medical students-a 5-year longitudinal study. Optom Vis Sci. 1996 Jul;73(7):495-8. 
19. Wu Y, Yi H, Liu W, Jia H, Eshita Y, Wang S et al. Risk factors for myopia in Inner Mongolia medical students in China. Open Journal of Epidemiology. 2012;2: 83-89.

20. Akrami A, Bakmohammad N, Seyedabadi M, Nabipour I, Mirzaei Z, Farrokhi S, et al. The association between school children intelligence. and refractive error. European Review for Med Pharm Sci.2012; 16; 908-912.
21. Gopalakrishnan S, Prakash MVS, Kumar Jha KR. A Study of Refractive Errors among Medical students in AIMST University, Malaysia. Indian Med J. 2001;105: 365-374.

22. Diether S, Gekeler F, Schaeffel F. Changes in contrast sensitivity induced by defocus and their possible relations to emmetropization in the chicken. Invest Ophthalmol Vis Sci. 2001 Nov; 42 (12): 3072-9.

\section{How to cite this article?}

N. Karthika, Kumari R, Kumar A. Refractory errors in medical students in a teaching hospital in rural Telangana. Trop J Ophthalmol Otolaryngol.2018;3(3):58-62.doi:10.17511/jooo.2018.i03.09 